\title{
Does breast feeding preterm babies within the first 24 hours lead to better outcomes?
}

\author{
*M H S M Hassan ${ }^{1}$, M N Lucas ${ }^{1,2}$, N Gamaathige ${ }^{1}$, W A A K Wickramasinghe ${ }^{3}$ \\ Sri Lanka Journal of Child Health, 2021; 51(1): 14-19 \\ DOI: http://dx.doi.org/10.4038/sljch.v51i1.9986
}

\begin{abstract}
Introduction: Breastfeeding is the optimal method of nutrition in preterm neonates. Studies done in other parts of the world suggest that babies who are breastfed within the first 24 hours have better outcomes. This is the first Sri Lankan study done about the outcomes of preterm babies who received breast milk within the first 24 hours.
\end{abstract}

Objectives: To compare the outcome of preterm neonates who received breast milk within the first 24 hours of life with those who received breast milk after 24 hours of age.

Method: Prospective, observational study was conducted on all neonates between 26-34 weeks gestation born at De Soysa Hospital for Women from 01.01.20 - 30.06.20. Ethics approval was obtained from the Sri Lanka College of Paediatricians. Data were collected using an interviewer administered questionnaire and data recording form. Babies, breastfed within 24 hours of life, were considered 'early' and after 24 hours were considered 'late'. Late breastfeeding occurred due to maternal medical conditions. Comparison between the groups was done using Chi-square test (SPSS version 22).

Results: Fifty-eight neonates with $17.2 \%, 13.8 \%$, $31.1 \%$ and $37.9 \%$ at $26-27,28-29,30-31$ and $32-34$ weeks of gestation and $1.7 \%, 27.6 \%, 56.9 \%, 12.1 \%$ and $1.7 \%$ with birth weights of $500-750 \mathrm{~g}, 751$ $1000 \mathrm{~g}, 1001-1500 \mathrm{~g}, 1501-2000 \mathrm{~g}$ and $>2000 \mathrm{~g}$ were included. Ten babies were excluded due to severe congenital abnormalities and contraindications to

${ }^{1}$ De Soysa Hospital for Women, Colombo, Sri Lanka, ${ }^{2}$ Department of Paediatrics, University of Colombo, Sri Lanka, ${ }^{3}$ Lady Ridgeway Hospital for Children, Colombo, Sri Lanka

*Correspondence: sharmyhassan@gmail.com

$$
\text { (iD) }
$$

https//orcid.org/ 0000-0002-5395-4882

(Received on 04 January 2021: Accepted after revision on 19 February 2021)

The authors declare that there are no conflicts of interest

Personal funding was used for the project.

Open Access Article published under the Creative

Commons Attribution CC-BY (c) (i) License breastfeeding. Thirty-four $(58.6 \%)$ babies were breastfed 'early' and 24 (41.4\%) were breastfed 'late'. Duration of central lines $(p=0.003, p<0.01)$, phototherapy $(\mathrm{p}=0.001, \mathrm{p}<0.01)$, hospital stay $(p=0.001, p<0.01)$, neonatal unit stay $(p=0.003$, $\mathrm{p}<0.01)$ and late onset sepsis $(\mathrm{p}=0.001, \mathrm{p}<0.01)$ were significantly lower in the 'early group'. The 'early group' achieved their birth weight faster $(\mathrm{p}=$ $0.003, \mathrm{p}<0.01)$ and had increased weight gain $(\mathrm{g} / \mathrm{kg} /$ day $)$ on discharge $(\mathrm{p}=0.001, \mathrm{p}<0.01)$. There was no significant differences in bone mineral status $(p=0.366)$ and incidence of necrotizing enterocolitis $(p=0.771)$ between the 2 groups.

Conclusions: Commencing breastmilk within the first 24 hours of life led to significantly better clinical outcomes in preterm babies between 26-34 weeks gestation.

(Key words: Very low birth weight, Extreme prematurity, Outcome, Complications, Sri Lanka)

\section{Background}

Preterm neonates have higher metabolic energy requirements compared to term infants due to higher risk of hypoxia, hypotension, acidosis, infections and surgeries ${ }^{1,2}$. Physiological immaturity of the gastrointestinal tract, decreased gut motility and reduced activity of intestinal enzymes also impose challenges for preterm growth ${ }^{3,4,5}$. Preterm neonates are born prior to the deposition of fat and glycogen stores and hence have minimal reserves. They also require essential fatty acids and higher glucose utilization for the comparatively larger brain surface area $^{6}$. Inadequate early postnatal nutrition results in abnormal neurodevelopment, growth failure and poor cognitive and behavioural outcomes ${ }^{6}$. Optimal nutrition is vital to achieve normal growth and minimize the growth restriction ${ }^{2}$. The goal is to achieve a growth rate that an infant is supposed to achieve in utero at the given gestational age, while minimising the complications of nutritional therapies $^{7,8}$. Recent studies have shown better outcomes with rapid advancement enteral feeds without increasing the risk of necrotizing enterocolitis (NEC) or feed intolerance ${ }^{9,10}$.

\section{Objectives}

The aim of the study was to determine if preterm babies born between 26 to 34 weeks gestation and fed breast milk within the first 24 hours of life have 
a better clinical outcome than those who were fed breastmilk after 24 hours of age.

\section{Method}

Study design, setting, period: A descriptive, prospective, observational study was conducted on all neonates, 26 to 34 weeks gestation, admitted to the neonatal unit at De Soysa Hospital for Women (DSHW), from 01.01.20 - 30.06.20.

Inclusion and exclusion criteria: Babies born alive, with birth weights more than $500 \mathrm{~g}$, between 26 and 34 weeks gestation, at DSHW, Colombo, within the study period, and who required admission to the neonatal unit were included in the study. Gestation was calculated based on the ultrasound scans done from 8 to 13 weeks of gestation. Babies with contraindications to breastfeeding, those with severe congenital anomalies that can affect growth and those with gastrointestinal related pathologies, like congenital diaphragmatic hernia or intestinal obstruction at birth, were excluded.

Study population: All babies who fulfilled the inclusion and exclusion criteria and whose parents gave informed written consent were included in the study.

All the mothers of the study participants were counselled about the importance of providing breastmilk for their baby and were encouraged to provide breast milk as soon as possible after delivery of their baby. All babies were given their own mother's expressed breast milk via cup or tube or directly fed from the breast. They were categorized into two groups according to the time the baby received the first enteral feed: the 'early group' received breast milk within 24 hours of birth and the 'late group' received breast milk after 24 hours of birth. The 'late group' was due to babies who received expressed breast milk after 24 hours due to maternal medical conditions.

Babies included in the study were followed up until discharge from the hospital and the clinical condition was assessed on a daily basis.

Clinical outcome was assessed by the presence of sepsis, NEC, central lines, hyperbilirubinaemia, duration of central lines, phototherapy, neonatal unit stay, hospital stay, weight gain on discharge, time taken to reach the birth weight and the bone mineral status. Assessment for NEC was done clinically by checking for the presence of abdominal distention accompanied by abdominal wall discolouration, or tension, or tenderness or reduced / absent bowel sounds on auscultation. Blood investigations, $\mathrm{x}$-rays and ultrasound scans were used to confirm the diagnosis in suspected patients. A positive blood culture with clinical features of sepsis was considered as proven sepsis. Two abnormal laboratory results with clinical suspicion of an infection, despite negative blood culture, was considered as probable sepsis ${ }^{11}$. Appearance of clinical features of sepsis within the first 72 hours of birth was taken as early sepsis and appearance of clinical features after 72 hours of birth was taken as late onset sepsis ${ }^{12}$. Hyperbilirubinaemia was taken as serum bilirubin levels above the phototherapy level according to the UK NICE guideline phototherapy charts. Phototherapy was commenced when the serum bilirubin exceeded the gestation specific NICE phototherapy level and stopped when the serum bilirubin was below the NICE phototherapy level. Bone mineral status was monitored 4 weekly or before discharge (if discharged before 4 weeks) with serum alkaline phosphatase and serum phosphate levels.

\section{Sample size calculation}

Sample size was calculated to compare early and late groups, referring to the study of 'Outcomes of early nutritional support in extremely low birth weight infants by Donovan et $a^{13}$ in 2006'.

$\mathrm{N}=\left[\left(1 / \mathrm{Q}_{1+} 1 / \mathrm{Q}_{2}\right) \mathrm{S}^{2}\left(\mathrm{Z} \alpha+\mathrm{Z}_{\mathrm{p}}\right)^{2}\right] / \mathrm{E}^{2}$

$\mathrm{E}=$ Estimated difference in means, $\mathrm{S}=$ Standard deviation, $\mathrm{Q}_{1}=$ Proportion of subjects in group one, $\mathrm{Q}_{2}=$ Proportion of subjects in group two, $\mathrm{Z} \alpha=\mathrm{Z}$ value corresponding to $\alpha$ error (1.96 for $\alpha$ of 0.05 ), $\mathrm{Zp}=\mathrm{Z}$ value corresponding to $\beta$ error $(0.84$ for $\beta$ of 0.2 ). Minimum required number per group was 17 .

Ethical issues: Ethical approval for the study was obtained from the Ethics Review Committee of Sri Lanka College of Paediatricians (No. SLCP/ ERC/ 2019/20). Informed written consent was obtained from the parents of the participating neonates.

Statistical analysis: Data were collected using an interviewer-administered questionnaire and data recording form. Outcomes were compared between "early" and "late" groups using Chi-square test (SPSS version 22).

\section{Results}

Sixty-eight babies were admitted to the neonatal unit during the study period, of which 10 were excluded due to congenital anomalies and critical illness. Fifty-eight babies were included in the study of whom 34 were in the 'early' group and 24 were in the 'late' group. Enteral feeding with unfortified expressed breast milk was commenced soon after birth and was increased as per amount expressed by the mother until full feeds $(200 \mathrm{ml} / \mathrm{kg} /$ day $)$ were reached in all stable babies. The volume of breast milk given on the first day ranged from 5 to 20 $\mathrm{ml} / \mathrm{kg} /$ day administered mostly via nasogastric tube in a 2-3 hour interval. Progression of rate and volume occurred in the range of $15-30 \mathrm{ml} / \mathrm{kg} /$ day and was done according to the availability of expressed breast milk given by the mother, who was supported by the health care staff. There were $56.9 \%$ females and $43.1 \%$ males. Most babies (63.8\%) were of Sinhalese ethnicity. There was no significant difference in the sociodemographic characteristics between the 'early' and the 'late' groups as shown in Table 1. 
Table 1: Comparison of sociodemographic characteristics between the 'early' and 'late' groups

\begin{tabular}{|c|c|c|c|c|c|}
\hline \multicolumn{2}{|r|}{ Variable } & Early $(n=34)$ & Late $(n=24)$ & Total $(n=58)$ & $\mathbf{p}$ \\
\hline \multirow{2}{*}{$\operatorname{Sex}$} & Male & 15 & 10 & 25 & \multirow{2}{*}{0.853} \\
\hline & Female & 19 & 14 & 33 & \\
\hline \multirow{3}{*}{ Ethnicity } & Sinhala & 24 & 13 & 37 & \multirow{3}{*}{0.309} \\
\hline & Tamil & 02 & 04 & 06 & \\
\hline & Muslim & 08 & 07 & 15 & \\
\hline \multirow{4}{*}{ Religion } & Buddhist & 22 & 12 & 34 & \multirow{4}{*}{0.502} \\
\hline & Hindu & 02 & 04 & 06 & \\
\hline & Islam & 08 & 07 & 15 & \\
\hline & Catholic & 02 & 01 & 03 & \\
\hline \multirow{4}{*}{ Age of mother } & $<20$ years. & 10 & 03 & 13 & \multirow{4}{*}{0.297} \\
\hline & $20-30$ years. & 17 & 13 & 30 & \\
\hline & $30-40$ years. & 07 & 07 & 14 & \\
\hline & $>40$ years. & 00 & 01 & 01 & \\
\hline \multirow{6}{*}{$\begin{array}{l}\text { Educational level } \\
\text { of the mother }\end{array}$} & No primary education & 00 & 02 & 02 & \multirow{6}{*}{0.316} \\
\hline & Grade $06-10$ & 07 & 02 & 09 & \\
\hline & Ordinary Level & 14 & 08 & 22 & \\
\hline & Advanced Level & 17 & 05 & 12 & \\
\hline & Diploma / Vocational training & 03 & 02 & 05 & \\
\hline & University Degree & 03 & 05 & 08 & \\
\hline \multirow{5}{*}{ Parity of mother } & 1 & 04 & 05 & 09 & \multirow{5}{*}{0.475} \\
\hline & 2 & 11 & 05 & 16 & \\
\hline & 3 & 11 & 11 & 22 & \\
\hline & 4 & 07 & 02 & 09 & \\
\hline & 5 & 01 & 01 & 02 & \\
\hline
\end{tabular}

Majority $(58.6 \%)$ of the mothers did not have medical complications. Most (55.2\%) babies in the study population were delivered by emergency caesarean section. Our study population consisted of $17.2 \%$ babies with extreme prematurity $(<28$ weeks gestation), $44.8 \%$ babies with severe prematurity (28-32 weeks gestation) and $37.9 \%$ babies with moderate prematurity (32-34 weeks gestation). Majority (56.9\%) of the babies had birth weights between $1.0-1.5 \mathrm{~kg}$. There was no statistical difference in the rate of maternal medical complications, mode of delivery, period of gestation or birth weight, between the 'early' and the 'late' groups as shown in Table 2.

Comparison of the clinical outcome of 'early' vs 'late' breast milk feeding is shown in Table 3 .

Table 2: Comparison of maternal factors and birth characteristics between 'early' and 'late' groups

\begin{tabular}{|c|c|c|c|c|c|}
\hline \multicolumn{2}{|r|}{ Variable } & $\begin{array}{l}\text { Early } \\
n=34\end{array}$ & $\begin{array}{l}\text { Late } \\
n=24\end{array}$ & $\begin{array}{l}\text { Total } \\
n=58\end{array}$ & $\mathbf{p}$ \\
\hline \multirow{5}{*}{$\begin{array}{l}\text { Maternal } \\
\text { medical } \\
\text { complications }\end{array}$} & Diabetes mellitus (DM) & 04 & 00 & 04 & \multirow{5}{*}{0.260} \\
\hline & Pregnancy induced hypertension $(\mathrm{PIH})$ & 04 & 07 & 11 & \\
\hline & $\mathrm{DM}+\mathrm{PIH}$ & 04 & 03 & 07 & \\
\hline & Other medical complications & 01 & 01 & 02 & \\
\hline & None & 21 & 13 & 34 & \\
\hline \multirow{2}{*}{$\begin{array}{l}\text { Mode of } \\
\text { delivery }\end{array}$} & Normal vaginal & 20 & 06 & 26 & \multirow{2}{*}{0.011} \\
\hline & Emergency caesarean section & 14 & 18 & 32 & \\
\hline \multirow{4}{*}{$\begin{array}{l}\text { Period of } \\
\text { gestation }\end{array}$} & $26-28$ weeks & 05 & 05 & 10 & \multirow{4}{*}{0.957} \\
\hline & 28-30 weeks & 05 & 03 & 08 & \\
\hline & 30-32 weeks & 10 & 08 & 18 & \\
\hline & 32-34 weeks & 14 & 08 & 22 & \\
\hline \multirow{5}{*}{ Birth weight } & $>2 \mathrm{~kg}$ & 01 & 00 & 01 & \multirow{5}{*}{0.318} \\
\hline & $1.5-2 \mathrm{~kg}$ & 11 & 05 & 16 & \\
\hline & $1.0-1.5 \mathrm{~kg}$ & 19 & 14 & 33 & \\
\hline & $0.75-1 \mathrm{~kg}$ & 02 & 05 & 07 & \\
\hline & $0.5-0.75 \mathrm{~kg}$ & 01 & 00 & 01 & \\
\hline
\end{tabular}


Table 3: Clinical outcome of 'early' vs 'late' breast milk feeding

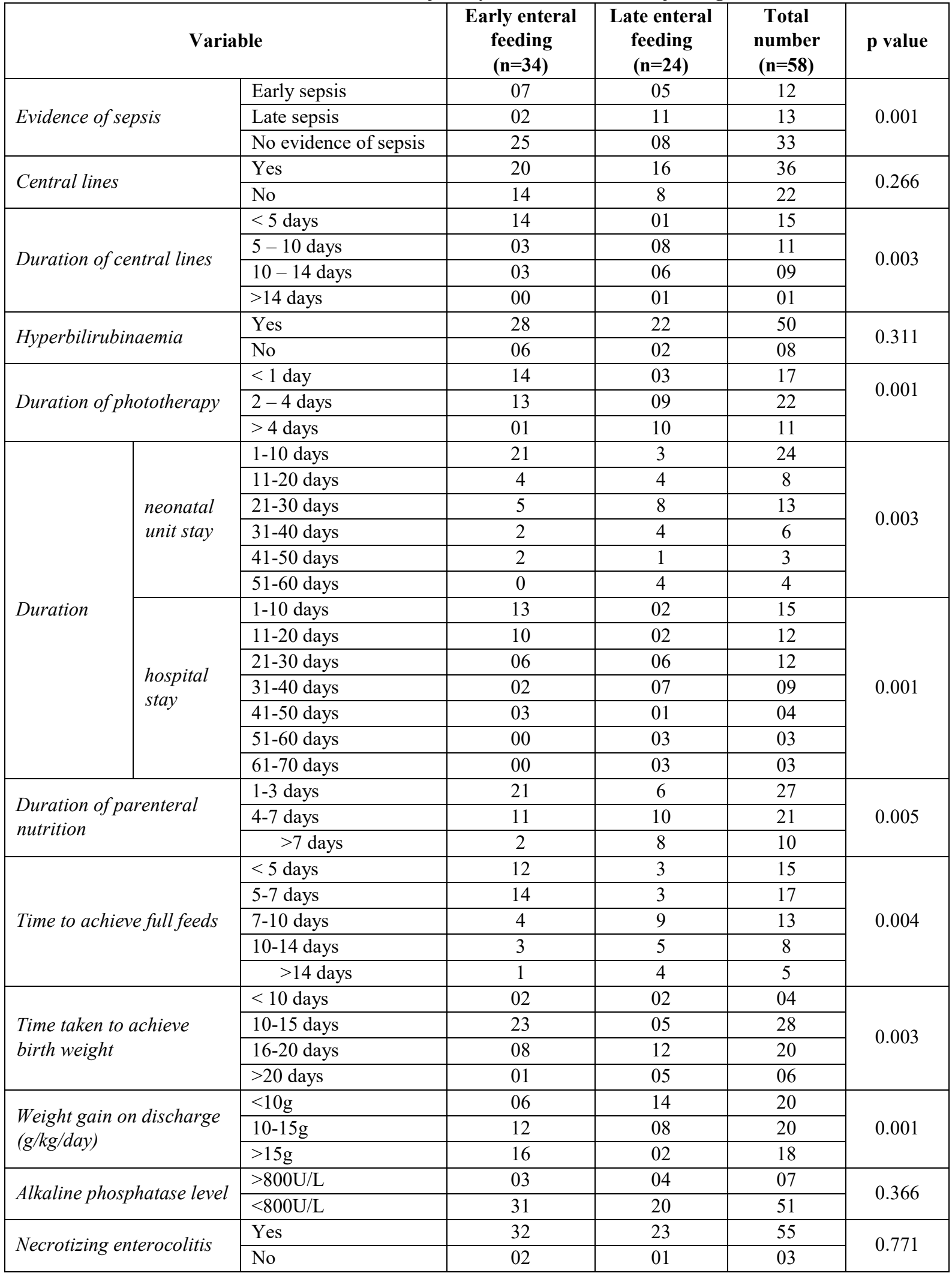

The prevalence of sepsis $(\mathrm{p}=0.001, \mathrm{p}<0.01)$ was significantly lower in the 'early' group. Most $(n=36$, $62 \%$ ) preterm neonates had central lines as part of their clinical management, 23 having umbilical venous catheters, 8 having umbilical artery catheters and 5 having both catheters. The 'early' group showed a significantly shorter duration of central lines $(p=0.003, p<0.01)$, although there was no significant difference in the presence of central lines $(p=0.266)$ between the 'early' and the 'late' group. 
The duration of phototherapy $(p=0.001, p<0.01)$ was significantly lower in the 'early' group although there was no significant difference in the presence of hyperbilirubinaemia $(\mathrm{p}=0.311)$. Two infants in each group had haemolytic disease of the newborn due to $\mathrm{ABO}$ incompatibility. There was no significant difference in the alkaline phosphatase levels ( $p=0.366$ ) between the 'early' and the 'late' groups. Serum phosphate levels were normal in all study participants.

The 'early' group had a significantly shorter duration of parenteral nutrition $(\mathrm{p}=0.005, \mathrm{p}<0.01)$ and reached full enteral feeds faster $(p=0.004$, $\mathrm{p}<0.01)$. There was no significant difference in the prevalence of NEC $(p=0.771)$ between the 'early' and the 'late' groups. All three babies who developed NEC showed complete recovery with medical management and did not develop any complications. The 'early' group showed a significantly shorter duration of stay both in the neonatal unit $(\mathrm{p}=0.003, \mathrm{p}<0.01)$ as well as in the hospital $(p=0.001, p<0.01)$. The longest stay in the neonatal unit was 60 days and in the hospital was 70 days. Weight gain, temperature control, cardiovascular and respiratory stability, competency of feeding expressed breast milk via cup and / or competency of direct breast feeding were requirements prior to discharge. Weight gain was calculated from the difference between the birth weight and the weight on discharge. Time taken to achieve the birth weight $(\mathrm{p}=0.003, \mathrm{p}<0.01)$ was significantly shorter and weight gain on discharge was significantly higher in the 'early' group.

\section{Discussion}

A retrospective study done in Israel, conducted by Flidel-Rimon O, et $a l^{14}$ during 1995-2001 on 440 very low birth weight babies, demonstrated a reduced risk for nosocomial sepsis without an increase in the occurrence of NEC, when early enteral feeding commencing from day 2 to 3 was practised. These results were similar to that of our study despite the fact that we compared before and after 24 hours. The Cochrane review conducted by Morgan $\mathrm{J}$, et $a l^{15}$ also revealed, that delaying enteral feeds did not reduce the risk of developing NEC in very preterm or VLBW infants.

A randomized controlled trial conducted by Karagol $\mathrm{BS}$, et $a l^{10}$, comparing slow vs rapid enteral feeding advancements on 92 preterm infants $<32$ weeks gestation with birth weights between 750-1250g revealed that rapid advancement significantly reduced the time to reach full feeds, the duration of parenteral nutrition, the rate of late onset sepsis and extra uterine growth restriction without increasing the occurrence of NEC or feed intolerance. These results are similar to that of our study where we advanced the feeds as per availability of expressed breast milk from the mother while providing her with the required lactational support and not on a predefined calculated increase of $\mathrm{ml} / \mathrm{kg} /$ day.

A randomised trial conducted by Dunn L, et $a l^{12}$ compared 19 infants in whom enteral feeds commenced at 48 hours with 20 infants who had not received enteral feeds for 9 days. It revealed that the group with early commencement of enteral feeds reached full feeds faster with a faster decline in the serum bilirubin levels with decreased duration of phototherapy and had lower alkaline phosphatase levels. These results are similar to the results of our study which showed significantly lower alkaline phosphatase levels and decrease duration of phototherapy. Dusick AM, et $a l^{7}$ showed that early enteral feeding resulted in a higher weight gain on discharge similar to the results of our study.

Early enteral feeding with colostrum and human milk has been found to promote the gut associated lymphoid tissue, which is the main source of mucosal immunity, prevent gastrointestinal atrophy and the overgrowth of enteropathogenic bacterial species which could translocate to the blood stream and cause sepsis, by minimising the period of fasting. Reaching full enteral feeds faster with early feeding also leads to improved growth with shorter time on intravenous devices and shorter duration parenteral nutrition, which has an immune suppressive action if given for over 2 weeks $^{14}$. All these are possible mechanisms of leading to lower incidence of sepsis in the 'early' group. Early feeding results in better enterohepatic circulation which in turn will help with faster clearance of the hyperbilirubinaemia ${ }^{16}$, explaining the shorter duration of phototherapy in the 'early' fed group.

\section{Conclusions}

Provision of breast milk within the first 24 hours improved the clinical outcome with lower incidence of sepsis, shorter duration of central lines, lower incidence of parenteral nutrition and phototherapy, better weight gain, shorter time to achieve full feeds and shorter hospital stay in preterm babies between 26-34 weeks of gestation.

\section{References}

1. Hay WW, Lucas A, Heird WC, Ziegler E, Levin E, Grave, G.D, et al. Workshop summary: nutrition of the extremely low birth weight infant. Pediatrics 1999; 104(6): 1360-8. https://doi.org/10.1542/peds.104.6.1360 PMid: 10585989

2. Schanler RJ, Garza C, Nichols BL. Fortified mothers' milk for very low birth weight infants: results of growth and nutrient 
balance studies. Journal of Pediatrics 1985; 107(3): 437-45.

https://doi.org/10.1016/S00223476(85)8053 $1-\mathrm{X}$

3. Berseth CL. Effect of early feeding on maturation of the preterm infant's small intestine. Journal of Pediatrics 1992; 120(6); 947-53.

https://doi.org/10.1016/S00223476(05)8196 9-9

4. Butte NF, Garza C, Smith EB, Nichols BL. Human milk intake and growth in exclusively breast-fed infants. Journal of Pediatrics 1984; 104(2): 187-95. https://doi.org/10.1016/S00223476(84)8099 $0-7$

5. Sinclair JC, Scopes JW, Silverman WA. Metabolic reference standards for the neonate. Pediatrics 1967; 39(5): 724-32.

6. Lucas MN. Preterm nutrition. Sri Lanka Journal of Child Health 2014; 43(1): 41-52. https://doi.org/10.4038/sljch.v43i1.6661

7. Dusick AM, Poindexter BB, Ehrenkranz RA, Lemons JA. Growth failure in the preterm infant: can we catch up? Seminars in Perinatology 2003; 27(4): 302-10. https://doi.org/10.1016/S01460005(03)0004 4-2

8. Agostoni C, Buonocore G, Carnielli VP, De Curtis M, Darmaun D, et al. Enteral nutrient supply for preterm infants: commentary from the European Society of Paediatric Gastroenterology, Hepatology and Nutrition Committee on Nutrition. Journal of Pediatric Gastroenterology and Nutrition 2010; 50(1); 85-91. https://doi.org/10.1097/MPG.0b013e3181ad aee 0

PMid: 19881390

9. Trang S, Zupancic JA, Unger S, Kiss A, Bando $\mathrm{N}$, et al. Cost-effectiveness of supplemental donor milk versus formula for very low birth weight infants. Pediatrics 2018; 141(3): e20170737. https://doi.org/10.1542/peds.2017-0737 PMid: 29490909

10. Karagol BS, Zenciroglu A, Okumus N, Polin RA. Randomized controlled trial of slow vs rapid enteral feeding advancements on the clinical outcomes of preterm infants with birth weight 750-1250g. Journal of
Parenteral and Enteral Nutrition 2013; 37(2): 223-8.

https://doi.org/10.1177/0148607112449482

PMid: 22664861

11. Zea-Vera A, Ochoa TJ. Challenges in the diagnosis and management of neonatal sepsis. Journal of Tropical Pediatrics 2015; 61(1): $1-3$

https://doi.org/10.1093/tropej/fmu079

PMid: 25604489 PMCid: PMC4375388

12. Dunn L, Hulman S, Weiner J, Kliegman R. Beneficial effects of early hypocaloric enteral feeding on neonatal gastrointestinal function: Preliminary report of a randomized trial. Journal of Pediatrics 1988; 112(4); 622-9.

https://doi.org/10.1016/S00223476(88)8018 5-9

13. Donovan R, Puppala B, Angst D and Coyle BW. Outcomes of early nutrition support in extremely low birth weight infants. Nutrition in Clinical Practice 2006; 21(4): 395-400. https://doi.org/10.1177/0115426506021004 395

PMid: 16870808

14. Flidel-Rimon O, Friedman S, Lev E, JusterReicher A, Amitay M, Shinwell ES. Early enteral feeding and nosocomial sepsis in very low birthweight infants. Archives of Disease in Childhood. Fetal and Neonatal Edition 2004; 89(4): F289-92.

https://doi.org/10.1136/adc.2002.021923

PMid: 15210657 PMCid: PMC1721698

15. Morgan J, Young L, McGuire W. Delayed introduction of progressive enteral feeds to prevent necrotising enterocolitis in very low birth weight infants. Cochrane Database Systematic Review 2014; 2014(12): CD001970.

https://doi.org/10.1002/14651858.CD00197 0.pub5

PMid: 25436902 PMCid: PMC7063979

16. de Vree JML, Romijn JA, Mok KS, MathusVliegen LMH, Stoutenbeek CP, Ostrow JD, et al. Lack of enteral nutrition during critical illness is associated with profound decrements in biliary lipid concentrations. American Journal of Clinical Nutrition. 1999; 70(1): 70-7. https://doi.org/10.1093/ajcn/70.1.70 PMid: 10393141 